\title{
Demographic and Psychological Predictors of Parent-Adolescent Communication About Sex: A Representative Statewide Analysis
}

\author{
Petra Jerman · Norman A. Constantine
}

Received: 16 November 2009/ Accepted: 28 April 2010/Published online: 11 May 2010

(C) The Author(s) 2010. This article is published with open access at Springerlink.com

\begin{abstract}
Sexual communication is a principal means of transmitting sexual values, beliefs, expectations, and knowledge between parents and children. Although this area has received considerable research attention, more studies with representative samples are needed to assure that findings are reflective of populations of interest. A representative statewide sample of households with adolescents $(N=907)$ from a large and diverse state in the United States was employed to examine the content and extent of sexual communication between parents and their adolescents, and the influence of selected primary demographic (age and gender), socio-demographic (Hispanic ethnicity, education, and religious attendance), and psychological (self-reported comfort, knowledge, and sexual communication difficulties) factors on the number of topics discussed. More than two-thirds of the parents reported experiencing some type of sexual communication difficulty, such as developmental concerns and embarrassment. Hierarchical regression results indicated that self-reported comfort, knowledge, and sexual communication difficulties strongly predicted the number of topics discussed, beyond the effect of demographic variables. These findings reinforce the notion that sexual communication between parents and adolescents can be universally challenging, and
\end{abstract}

P. Jerman $(\varangle) \cdot$ N. A. Constantine

Center for Research on Adolescent Health and Development,

Public Health Institute, Oakland, CA, USA

e-mail: pjerman@phi.org

\section{N. A. Constantine}

Division of Community Health and Human Development, School of Public Health, University of California, Berkeley, CA, USA

e-mail: nconstantine@ berkeley.edu parents of both genders, all ages, and all socio-demographic characteristics might benefit from education and support.

Keywords Parent-adolescent communication .

Sex education - Representative sample .

Demographic predictors Psychological predictors

\section{Introduction}

Research on child development in the family context and on parent-child relationships has expanded over the last 20 years (the terms child and children are used in this article to refer to offspring aged 18 years and younger). The accumulated evidence strongly suggests that parental nurturance and involvement can enhance children's receptivity to parental influence, thereby enabling more effective socialization (Steinberg 2001). One type of socialization that typically occurs within families is sexual socialization, with parents teaching and influencing their children about physical development, physical affection, modesty, nudity, gender differences, sexual behaviors, and marriage, among other topics (Lefkowitz and Stoppa 2006; Shtarkshall et al. 2007). Parent-child communication about sexual issues, or sexual communication, is an important aspect of sexual socialization.

Communication is a fundamental process through which parents convey ideas, values, beliefs, expectations, information, and knowledge to their children. Parents typically have the opportunity to communicate with their children on a daily basis, and as such, parents can play a critical role in shaping their children as they move into adolescence and eventually into adulthood. Many parents would like to communicate with their children about sexual issues, but 
they do so superficially or not at all, because they lack necessary communication skills, knowledge, or comfort (Constantine et al. 2007; Dilorio et al. 2003; Lefkowitz and Stoppa 2006). Although research results on the effects of parental communication on their children's sexual behavior have been mixed (see DiIorio et al. 2003), several studies have shown that sexual socialization achieved through parental nurturance and involvement is associated with children's remaining abstinent, postponing intercourse, having fewer sexual partners, and using contraception more consistently (DiIorio et al. 2003; Markham et al. 2010; Miller et al. 2001). As Whitaker et al. (1999) found, sexual communication between parents and children is most likely to reduce children's sexual risk when parents are open, skilled, and comfortable in their discussion of sex-related topics.

Demographic characteristics of parents and children can influence parent-child sexual communication. Gender of the parent and the child has been related to sexual communication, with mothers being more likely to talk with their children about sexual topics than are fathers, and mothers being more likely to talk with daughters than with sons and fathers more likely to talk with sons than with daughters (DiIorio et al. 2003; Swain et al. 2006). Swain et al. (2006) found that the gender mix of parents and children was the strongest demographic indicator of parent-child sexual communication in their study: Mothers reported communicating with their child about the negative consequences of sex and where to obtain birth control to a greater extent than fathers did, with the most discussion occurring between mothers and daughters. Age of the child also has been found to influence sexual communication, with less frequent and extensive communication occurring with younger children (Byers et al. 2008; Eisenberg et al. 2006). Overall, research suggests that children's age, and children's gender interacting with parents' gender, do predict sexual communication.

Some evidence of associations between sexual communication and parents' race and ethnicity and socioeconomic status has been found, although findings have been inconsistent (DiIorio et al. 2003; Pluhar et al. 2008; Swain et al. 2006). Greater frequency of sexual communication has been reported among Black versus White or Hispanic parents, as well as among Black and White versus Hispanic parents (DiIorio et al. 2003). Swain et al. (2006) found that low-income, non-White parents reported more discussion with their children about the negative consequences of sex and where to obtain birth control than did high-income, White parents. Swain et al. also found that politically conservative parents who attend religious services more than once per week reported discussing the negative consequences of sex with their adolescent more often than did parents who attend religious services rarely or never and liberal parents who attend religious services 1-4 times per month. An absence of correlation between discussion about AIDS and mothers' education, employment status, or household income has also been reported (Dilorio et al. 2003), and among African American mothers, socioeconomic variables such as education and income were found not to predict mother-child sexual communication (Pluhar et al. 2008). Overall, research evidence is inconclusive as to the association between parents' racial, ethnic, and socioeconomic characteristics and their sexual communication with their children.

Byers et al. (2008) found parental demographic characteristics to be weaker predictors of parents' sexual communication with their children in grades K-8 as compared with other parental characteristics, such as parents' own sexual education and parents' sexual knowledge and comfort. Similarly, African American mothers reporting greater comfort and self-efficacy for communicating about sexuality with their 6 to 12-year-old children reported more frequent sexual communication (Pluhar et al. 2008). Lehr et al. (2005) studied sexual communication between fathers and sons and found that fathers' sexual communication with their own father was an important predictor of sexual communication. Dilorio et al. (2003) noted that other studies also have shown that parents' sexual knowledge or perception of their knowledge level, as well as their comfort level, influence the extent to which parents discuss sex with their children. Furthermore, parents' sexual knowledge and comfort have been related to the extent of parental communication about various specific sexual health topics (Byers et al. 2008; Lehr et al. 2005; Miller et al. 2007). Overall, research evidence suggests that parents' knowledge and comfort and their own childhood experiences with sexual education and communication are strongly associated with whether, how often, and how much parents talk with their children about sexual topics.

Several factors that can interfere with parents' communication with their children about sexual issues have been proposed in the literature. Jaccard et al. (2000) identified five main categories of predictors of mothers' reservations in sexual communication with their children: having the necessary knowledge and skills to explain sexual topics, adopting a cooperative orientation toward mutual communication, perceived self-efficacy of communication, situational constraints, and fear of encouraging sexual activity. The two strongest individual predictors were concerns over embarrassment (within the category of necessary knowledge and skills) and being taken seriously by the adolescent (within the category of adopting a cooperative orientation). In a study of Latina mothers and their adolescent children, cultural support versus nonsupport for open discussion about sex in the home was found to play a large role in mother-child conversations about sex 
(Guilamo-Ramos et al. 2006). Other factors that can limit parents' sexual communication with their children have also been reported, including lack of an opportune time, lack of confidence, a child being too young, and the perception that the child is unreceptive (Jaccard et al. 2002; Miller et al. 2007; Wilson et al. 2010).

\section{Research Questions and Hypotheses}

Research on sexual communication between parents and their children dates back about three decades. But as Lefkowitz (2002) noted, it can be difficult to obtain willing samples due to the sensitive nature of this topic, and representative samples are needed to assure that researchers are capturing perspectives, behaviors, and associations that reflect those of the populations of interest. Adding to a literature with few representative-sample studies on parent-child sexual communication, we report on the present study that employed a representative statewide sample of households with children aged 8-18 years from a large and diverse state in the United States to investigate aspects of parent's communication about sex with their preadolescent and adolescent children. In the remainder of this article, we use the terms adolescent and adolescents to refer to the pre, early, middle, and late adolescents who were the focus of the questions asked of their parents.

First, we examined the extent to which parents report communicating with their adolescents about sex and sexuality, together with their perceived levels of comfort and knowledge in this sexual communication. In addition, we explored the extent to which parents report difficulties in communicating with their adolescents about sex and sexuality and the types of difficulties they report. Finally, we examined the predictability of sexual communication by demographic characteristics of parents and adolescents, as well as the additional predictive power of parents' perceived levels of comfort, knowledge, and difficulties experienced.

On the basis of the prior research discussed above, we hypothesized that adolescent and parent age, adolescent and parent gender, parent Hispanic ethnicity, parent education, and parent religious attendance in a typical month would predict extent of sexual communication, that adolescent gender would moderate the effect of parent gender, and that self-reported levels of comfort, knowledge, and difficulties experienced would add additional predictive power when demographic factors are controlled. More specifically, we expected that the number of topics discussed would be greater for parents of older adolescents. We also expected that mothers would report a greater number of topics discussed than would fathers, and that mothers would be more likely to talk with daughters than would fathers, and that fathers would be more likely to talk with sons than would mothers. We also predicted that Hispanic parents, parents with lower educational levels, and parents with more frequent religious attendance would discuss fewer topics. Finally, we expected that parents who report lower levels of comfort and knowledge and parents who report a sexual communication difficulty would talk about fewer topics.

\section{Method}

This study employed a subset of data from a list-assisted, random-digit-dial statewide survey we conducted on parental beliefs, preferences, and practices regarding sexuality education and adolescent sexual health services in California (Constantine et al. 2007). The Public Health Institute's institutional review board reviewed the survey instrument and protocol and declared them exempt. Data collection took place in the spring and summer of 2006.

\section{Sampling}

The sampling frame was based on the population of all households with a telephone in California. The person answering the phone was asked the number of adults and the number of children aged 18 years and younger in the household, and to identify a parent in the household. If a parent was available, he or she was read the informed consent script and then invited to participate. Follow-up appointments were made if the parent was unable to complete the interview at that time. Initial calls were conducted in English, and Spanish-speaking interviewers called back respondents who spoke Spanish. At least ten calls were made to consistently unanswered or busy phone numbers and answering machines.

The total sample consisted of 1,284 parents who completed interviews. A response rate of $53 \%$ was calculated using the RR3 method of the American Association for Public Opinion Research (2006). This method divides the number of completed interviews by the estimated number of eligible households called, which is estimated by a formula involving known eligible and ineligible households, and those of unknown eligibility. The total sample was based on subsampling within California's five allinclusive regions consisting of groups of counties organized by geographic and demographic similarity. To compensate for the difference in selection probabilities resulting from higher sampling rates in smaller regions, we used stratum weights in this study's statewide analyses. The resulting design effect attributable to weighting was minimal (1.13). 


\section{Participants}

For the present study, we used a subset of interviews consisting of the 907 parents who had a child between the ages of 8 and 18 years. Demographic data collected about the responding parents included gender, age, Hispanic ethnicity, race, education, and religious attendance in a typical month. Three-fourths of the parents were female, and almost two-thirds were aged 40 years or older. Fortyfour percent of the parents were Hispanic, and $40 \%$ were non-Hispanic White. In answering the questions used in the present study, parents were asked to focus on their child or one of their children who was between the ages of 8 and 18 years. Demographic data collected about the adolescents included age and gender. The mean age of the adolescents was 12.9 years, and $51.4 \%$ were male. For several analyses, adolescents' ages were collapsed into four categories: preadolescent (ages 8-10 years), early adolescent (ages 11-13 years), middle adolescent (ages 14-16 years), and late adolescent (ages 17-18 years). Because the late-adolescent age category comprised just 2 years, whereas the other three age categories comprised 3 years, fewer adolescents are included in this category than in the others. The demographic characteristics of the responding parents and the adolescents are presented in Table 1.

\section{Measurement}

As one part of the interview, we asked parents to respond to a series of three closed-ended and one open-ended question about sexual communication. The first closed-ended question was, "Thinking about your $n n$ year-old, have you ever talked with him (or her) about... (a) the basic facts of human reproduction, (b) issues involved in becoming sexually active, (c) the advantages for a young person of avoiding sexual intercourse, (d) HIV/AIDS and other sexually transmitted infections (STIs), (e) the importance of using protection, such as condoms, to prevent pregnancy or diseases if he (or she) becomes sexually active, and (f) where to get condoms?" Response options were "yes" and "no." Using the six dichotomous sex education topics, we constructed a 6-item summated scale for number of topics discussed. This scale yielded a coefficient alpha of .86 and a Mokken scale analysis homogeneity coefficient of .73.

The second closed-ended question was, "Overall, how comfortable do you feel talking with your $n n$ year-old about sex and relationships?" Response options were very comfortable, somewhat comfortable, somewhat uncomfortable, and very uncomfortable. The third closed-ended question was, "And how knowledgeable do you feel talking with your $n n$ year-old about sex and relationships?" Response options were very knowledgeable, somewhat
Table 1 Demographic characteristics of survey respondents and adolescents $(N=907)$

\begin{tabular}{|c|c|c|}
\hline Demographic characteristic & $n$ & $\%$ \\
\hline \multicolumn{3}{|l|}{ Parent gender } \\
\hline Male & 219 & 24.2 \\
\hline Female & 688 & 75.8 \\
\hline \multicolumn{3}{|l|}{ Parent age } \\
\hline Under 30 & 58 & 6.4 \\
\hline $30-39$ & 279 & 30.7 \\
\hline $40-49$ & 382 & 42.1 \\
\hline 50 and over & 186 & 20.5 \\
\hline Missing & 3 & 0.3 \\
\hline \multicolumn{3}{|l|}{ Parent race and ethnicity } \\
\hline Hispanic & 397 & 43.8 \\
\hline White, non-Hispanic & 359 & 39.6 \\
\hline Asian American & 55 & 6.0 \\
\hline African American, non-Hispanic & 52 & 5.7 \\
\hline Other, non-Hispanic & 36 & 3.9 \\
\hline Missing & 9 & 1.0 \\
\hline \multicolumn{3}{|l|}{ Parent education } \\
\hline Less than high school & 163 & 18.0 \\
\hline High school or GED & 254 & 28.1 \\
\hline Some college & 179 & 19.7 \\
\hline College & 183 & 20.2 \\
\hline Graduate school & 126 & 13.8 \\
\hline Missing & 1 & 0.1 \\
\hline \multicolumn{3}{|c|}{ Parent religious attendance in a typical month } \\
\hline Rarely & 250 & 27.5 \\
\hline Few times per year & 160 & 17.6 \\
\hline $1-3$ times per month & 144 & 15.8 \\
\hline 1 time per week & 236 & 26.0 \\
\hline More than 1 time per week & 108 & 11.9 \\
\hline Missing & 10 & 1.1 \\
\hline \multicolumn{3}{|l|}{ Adolescent gender } \\
\hline Male & 466 & 51.4 \\
\hline Female & 441 & 48.6 \\
\hline \multicolumn{3}{|l|}{ Adolescent age group } \\
\hline Preadolescent (ages 8-10 years) & 251 & 27.7 \\
\hline Early adolescent (ages 11-13 years) & 255 & 28.1 \\
\hline Middle adolescent (ages $14-16$ years) & 256 & 28.3 \\
\hline Late adolescent (ages $17-18$ years) & 144 & 15.9 \\
\hline
\end{tabular}

Numbers and percentages are weighted

knowledgeable, somewhat unknowledgeable, and very unknowledgeable.

The open-ended question was, "What is the most difficult part for you in talking to your child about sex and relationships?" Interviewers probed for clarity as necessary and entered the parents' responses into the database verbatim. A professional translator later translated the Spanish-language responses, and a second professional 
translator reviewed the translations for accuracy. Open coding was used to develop substantive categories for parents' responses to this question. Category development was based on the specific concepts that emerged from open coding and was guided by our general knowledge of the literature. The parents' responses were coded for what we judged to be the most salient difficulty. The first author independently coded all of the responses and developed a coding dictionary. The second author subsequently coded all of the responses, all differences were resolved (resulting in $100 \%$ agreement), and the coding dictionary was revised.

\section{Results}

\section{Analytic Plan}

Quantitative analyses were performed using SPSS 15.0 for Windows. We used frequencies and cross-tabulations to summarize the number of topics discussed, parents' perceived levels of comfort and knowledge in sexual communication, and the difficulties parents reported in sexual communication. Statistical significance, at an alpha level of .05 , was assessed by Chi-square test (for expected frequencies of fewer than five, we used Fisher's exact test or, if computational limits were reached, the Monte Carlo approximation).

We also employed hierarchical regression analyses to examine the relationships between parent and adolescent primary demographic variables, socio-demographic variables, parent perceived comfort and knowledge regarding sexual communication, and parent reported sexual communication difficulties, with the dependent variable number of topics discussed. Because of insufficient sample sizes in the race categories other than White, only the Hispanic versus non-Hispanic ethnicity variable was included in the regression analyses, whereas the non-Hispanic race categories reported in Table 1 were not used. Listwise deletion for missing values was employed for all variables (missing between 0 and $1.1 \%$ ) except the openended item on sexual communication difficulties (missing of $7.2 \%$ ), for which missing was included as one of two dummy variables (presence of difficulties and missing, vs. the reference category absence of difficulties) to allow for testing the effect of not answering this question. In addition, adolescent gender and parent gender individually and in combination were included to allow for testing of the hypothesized parent-adolescent gender interaction. An alpha level of .05 was used to evaluate statistical significance. Indices of multicollinearity (eigenvalues, condition indices, and variance proportions) were examined, and no problems were identified.
Descriptive Data

Fifteen percent of parents did not discuss with their adolescent any of the six sex education topics we asked about, and $26 \%$ of parents discussed all six topics. The mean number of topics discussed was 3.5 out of 6 topics. The greatest proportion of parents $(73.8 \%)$ said they discussed human reproduction; $70.6 \%$ discussed HIV/AIDS and other STIs, $64.5 \%$ avoiding sexual intercourse, $57.4 \%$ becoming sexually active, $52.2 \%$ using protection, and $33.4 \%$ where to get condoms.

Table 2 presents the percentage of parents who discussed each of the six topics with their adolescents, and mean numbers of topics discussed, by parent gender and by adolescent age level and gender. Significant differences were found among both mothers and fathers in the percentage who discussed the six topics with daughters versus sons at different age levels $(p<.05)$. The mean number of topics discussed by both mothers and fathers increased as adolescent age level increased. Mothers discussed a greater number of topics with preadolescent and early adolescent daughters than did fathers. The mean number of topics discussed with middle adolescent sons was greater for fathers than for mothers. Further, mothers discussed a greater number of topics with late adolescents than did fathers.

Some gender-related communication patterns on specific topics were observed. A greater proportion of fathers discussed avoiding sex with preadolescent and early adolescent daughters than with preadolescent and early adolescent sons. For late adolescence, a greater proportion of fathers discussed HIV/AIDS and other STIs with daughters than with sons, but a greater proportion discussed using protection with sons than with daughters. Among mothers, a greater proportion discussed condoms with sons than with daughters in early, middle, and late adolescence. In addition, $100 \%$ of mothers discussed avoiding sex with late adolescent daughters, as compared with $79 \%$ who discussed the topic with late adolescent sons.

In response to the questions about how comfortable they feel in talking with their adolescent about sex and relationships, $52.4 \%$ of parents said they feel very comfortable, $25.8 \%$ said they feel somewhat comfortable, $15.3 \%$ said they feel somewhat uncomfortable, and 5.8\% said they feel very uncomfortable (missing $=0.7 \%, N=907$ ). In response to the questions about how knowledgeable they feel in talking with their adolescent about sex and relationships, $59.5 \%$ of parents said they feel very knowledgeable, $32.3 \%$ said they feel somewhat knowledgeable, 4.9\% said they feel somewhat unknowledgeable, and 3.3\% said they feel very unknowledgeable (missing $=0.8 \%$, $N=907)$. In response to the open-ended question about 
Table 2 Percentage of fathers and mothers who have discussed selected sex education topics with their adolescent by adolescent age level and gender

\begin{tabular}{|c|c|c|c|c|c|c|c|}
\hline $\begin{array}{l}\text { Adolescent age level } \\
\text { and gender }\end{array}$ & $\begin{array}{l}\text { Human } \\
\text { reproduction }\end{array}$ & $\begin{array}{l}\text { Becoming } \\
\text { sexually active }\end{array}$ & $\begin{array}{l}\text { Avoiding } \\
\text { sex }\end{array}$ & $\begin{array}{l}\text { HIV/AIDS } \\
\text { and other STIs }\end{array}$ & $\begin{array}{l}\text { Using } \\
\text { protection }\end{array}$ & $\begin{array}{l}\text { Where to } \\
\text { get condoms }\end{array}$ & $\begin{array}{l}\text { Mean \# } \\
\text { of topics }\end{array}$ \\
\hline \multicolumn{8}{|l|}{ Fathers } \\
\hline \multicolumn{8}{|l|}{ Preadolescent } \\
\hline Sons $(n=37)$ & 54.1 & 21.6 & 27.0 & 37.8 & 16.7 & 11.1 & 1.71 \\
\hline Daughters $(n=29)$ & 62.1 & 16.7 & 31.0 & 34.5 & 13.8 & 0.0 & 1.59 \\
\hline \multicolumn{8}{|l|}{ Early adolescent } \\
\hline Sons $(n=19)$ & 78.9 & 57.9 & 57.9 & 78.9 & 47.4 & 30.0 & 3.46 \\
\hline Daughters $(n=27)$ & 66.7 & 48.1 & 64.3 & 71.4 & 32.1 & 23.1 & 3.06 \\
\hline \multicolumn{8}{|l|}{ Middle adolescent } \\
\hline Sons $(n=44)$ & 88.6 & 75.0 & 81.8 & 86.0 & 75.0 & 59.1 & 4.64 \\
\hline Daughters $(n=29)$ & 75.9 & 70.0 & 80.0 & 73.3 & 60.0 & 35.7 & 3.95 \\
\hline \multicolumn{8}{|l|}{ Late adolescent } \\
\hline Sons $(n=21)$ & 78.9 & 81.0 & 80.0 & 81.0 & 81.0 & 45.0 & 4.40 \\
\hline Daughters $(n=13)$ & 84.6 & 76.9 & 76.9 & 92.3 & 53.8 & 38.5 & 4.22 \\
\hline$p$ & .024 & .000 & .000 & .000 & .000 & .000 & \\
\hline \multicolumn{8}{|l|}{ Mothers } \\
\hline \multicolumn{8}{|l|}{ Preadolescent } \\
\hline Sons $(n=92)$ & 52.2 & 25.3 & 30.4 & 38.0 & 16.5 & 7.7 & 1.71 \\
\hline Daughters $(n=93)$ & 53.8 & 26.9 & 33.3 & 44.1 & 19.1 & 8.5 & 1.85 \\
\hline \multicolumn{8}{|l|}{ Early adolescent } \\
\hline Sons $(n=108)$ & 73.8 & 53.7 & 63.2 & 65.7 & 52.8 & 31.8 & 3.40 \\
\hline Daughters $(n=101)$ & 84.2 & 67.3 & 72.3 & 78.2 & 53.5 & 25.7 & 3.81 \\
\hline \multicolumn{8}{|l|}{ Middle adolescent } \\
\hline Sons $(n=84)$ & 83.3 & 75.0 & 82.1 & 90.5 & 73.8 & 48.8 & 4.53 \\
\hline Daughters $(n=99)$ & 88.9 & 76.8 & 85.9 & 90.9 & 74.7 & 46.5 & 4.63 \\
\hline \multicolumn{8}{|l|}{ Late adolescent } \\
\hline Sons $(n=62)$ & 75.8 & 75.8 & 79.0 & 90.3 & 83.9 & 67.7 & 4.70 \\
\hline Daughters $(n=48)$ & 87.8 & 89.8 & 100.0 & 93.8 & 85.7 & 63.8 & 5.20 \\
\hline$p$ & .000 & .000 & .000 & .000 & .000 & .000 & \\
\hline
\end{tabular}

STIs sexually transmitted infections. Significance values are for Chi-square test of adolescent age level by adolescent gender

the most difficult part in talking with their adolescent about sex and relationships, $70.1 \%$ of parents reported experiencing difficulties (absence of difficulties $=22.8 \%$, missing $=7.2 \%, N=907$ ). Through open coding of these responses, we identified nine categories of sexual communication difficulties.

The first category comprised difficulties related to embarrassment or discomfort, whether parents' selfreported embarrassment or discomfort or perceived adolescent's embarrassment or discomfort (e.g., "I think that it is just a comfort level that you feel, because it is a topic we are not in the habit of discussing" and "They [children] are embarrassed over girls menstruating.") The second category comprised difficulties related to knowledge and selfefficacy (e.g., "It is difficult for me to talk with her; I fear that I may explain something poorly to her or give her incorrect information.").
We labeled the third category cultural and social influences or issues, which included cultural influences or issues (e.g., "I think that sexual relations are a very delicate subject due to our culture"), societal and social environment influences or issues (e.g., "The hard part is that what TV and culture are showing them is not real life; it's me against the media"), religious influences or issues (e.g., "Not scaring her and explaining how God sees it and how the world sees it and the difference in that"), and gender influences or issues (e.g., "That is a certain taboo...as a father with my daughters I feel a bit uncomfortable, something that I leave in the hands of my wife and she talks with them.") The fourth category involved family and intergenerational influences or issues (e.g., "It's difficult for me because they never told me anything about this subject and what I learned, I learned at school because in my house one did not use to talk about this subject.”). 
The fifth category involved general communication issues with one's adolescent, including initiating talks about sex and relationships and the adolescent not listening (e.g., "I think just to bringing it up in a comfortable time" and "Knowing whether he's listen. He's 13 going on ugly. I guess he gets a lot of peer pressure from his friends...I guess he's listening...sometimes.") The sixth category comprised difficulties related to parental influence or control issues (e.g., "Knowing that the kids are going to do it regardless of what you say and wanting them to be safe and make wise choices.") Difficulties related to accepting one's adolescent's sexuality (e.g., "Imagining that someday she's going to have it [sex]") comprised the seventh category.

The eighth category involved issues related to age or development, including developmental-cognitive issues, being afraid of promoting sex and taking away innocence, and being unsure of the amount of information to provide (e.g., "Judging how much to tell them for their age, age appropriateness of the subject, how to judge what is and isn't [appropriate]" and "I look for opportunities to talk to him, but I don't want to put ideas in his head or bring things up that he is not thinking about naturally.") Finally, the ninth category encompassed difficulties in talking about specific topics (e.g., "About using protection when I want him to be abstinent" and "Probably the whole relationship part, having respect for the other person.").

Table 3 presents the sexual communication difficulty categories, in order of total frequency, by adolescent age level and gender, for both mothers and fathers. Categories that totaled to less than $5 \%$ within each parent-gender subgroup, and across adolescent age levels and genders, were combined into an Other category. Significant differences were observed by adolescent age level and gender in the percentage of parents who reported experiencing the noted difficulties $(p<.001)$. Age or developmental issues were the most common among both mothers and fathers of younger adolescents. Embarrassment or discomfort was greater with older adolescents for both mothers and fathers. General communication issues, such as initiating discussions and getting past the adolescent's "know-it-all" attitude, were more common among fathers than mothers of late adolescents.

\section{Regression Analyses}

As indicated in the Analytic Plan section, parent and adolescent primary demographic variables, socio-demographic variables, parent perceived comfort and knowledge regarding sexual communication, and parent reported sexual communication difficulties were entered into a series of hierarchical regressions as predictors of number of topics discussed.

Model 1 included the four primary demographic variables_-adolescent age, adolescent gender, parent age, and parent gender, as well as the parent-adolescent gender interaction, $F(5,869)=78.166, p=.000$. Adolescent age and the parent-adolescent gender interaction were significant. Across all adolescent age levels, number of topics discussed was consistently higher when the gender of the parent and the gender of the adolescent matched. Probing of the significant parent-adolescent gender interaction following the procedure outlined by Hayes and Matthes (2009) indicated a conditional effect of parent gender on

Table 3 Sexual communication difficulty categories by adolescent age level and gender for fathers and mothers

\begin{tabular}{|c|c|c|c|c|c|c|c|c|c|}
\hline \multirow{2}{*}{$\begin{array}{l}\text { Sexual communication } \\
\text { difficulty category }\end{array}$} & \multicolumn{2}{|c|}{ Preadolescent } & \multicolumn{2}{|c|}{ Early adolescent } & \multicolumn{2}{|c|}{ Middle adolescent } & \multicolumn{2}{|c|}{ Late adolescent } & \multirow[t]{2}{*}{ Total \% } \\
\hline & Sons \% & Daughters \% & Sons \% & Daughters \% & Sons \% & Daughters \% & Sons \% & Daughters \% & \\
\hline \multicolumn{10}{|l|}{ Fathers $(p<.001)$} \\
\hline Age or developmental issues & 51.6 & 34.5 & 17.6 & 4.2 & 8.1 & 15.4 & 0.0 & 0.0 & 19.1 \\
\hline General communication issues & 16.1 & 0.0 & 5.9 & 4.2 & 13.5 & 15.4 & 40.0 & 40.0 & 14.4 \\
\hline Issues with specific topic & 3.2 & 6.9 & 17.6 & 25.0 & 27.0 & 7.7 & 0.0 & 0.0 & 12.4 \\
\hline Embarrassment or discomfort & 3.2 & 10.3 & 0.0 & 8.3 & 10.8 & 23.1 & 15.0 & 10.0 & 10.3 \\
\hline Gender influences or issues & 0.0 & 17.2 & 5.9 & 12.5 & 0.0 & 15.4 & 0.0 & 10.0 & 7.2 \\
\hline Other & 3.2 & 13.7 & 0.0 & 25.1 & 18.9 & 3.8 & 25.0 & 10.0 & 12.8 \\
\hline \multicolumn{10}{|l|}{ Mothers $(p<.001)$} \\
\hline Age or developmental issues & 41.7 & 43.4 & 13.8 & 19.8 & 6.0 & 7.1 & 0.0 & 2.6 & 18.1 \\
\hline Issues with specific topic & 19.4 & 10.5 & 14.9 & 8.1 & 13.4 & 16.5 & 8.6 & 7.7 & 12.8 \\
\hline Embarrassment or discomfort & 4.2 & 5.3 & 13.8 & 11.6 & 16.4 & 11.8 & 17.2 & 15.4 & 11.6 \\
\hline General communication issues & 1.4 & 3.9 & 8.0 & 5.8 & 10.4 & 18.8 & 17.2 & 12.8 & 9.5 \\
\hline Family and intergenerational issues & 5.6 & 6.6 & 6.9 & 9.3 & 11.9 & 9.4 & 10.3 & 5.1 & 8.2 \\
\hline Other & 16.8 & 15.6 & 11.3 & 11.7 & 23.9 & 15.4 & 27.6 & 12.8 & 16.5 \\
\hline
\end{tabular}


number of topics discussed for female adolescent gender, such that mothers communicated with daughters about sex education topics to a significantly greater extent than fathers did $(B=0.6746$, SE $B=0.210, t(5,872)=3.214$, $p=.001)$, but not for male adolescent gender $(B=0.098$, SE $B=0.193, t(5,872)=0.507, p=.613)$.

Model 2 added the three socio-demographic variables (parent Hispanic ethnicity, parent education, and parent religious attendance in a typical month) to Model $1, F_{\text {inc }}(3$, $866)=1.261, p=.287$. None of the three variables added significantly to the prediction provided by age and gender. Finally, Model 3 added the three psychological variablesparent perceived comfort, parent perceived knowledge, and parent-reported sexual communication difficulties (coded as two dummy variables, presence of difficulties and missing, vs. the reference category absence of difficulties)—to Model 2, $F_{\text {inc }}(4,862)=54.169, p=.000$. All of these variables were significant after adjusting for the primary and the socio-demographic variables. The regression analyses results are presented in Table 4.

\section{Discussion}

Adolescence is a developmental period marked by sexual discovery and often by sexual risk. A principal means for transmitting sexual values, beliefs, expectation, and knowledge between parents and their adolescents is sexual communication. This communication is most likely to promote healthy sexual development and reduce sexual risk when parents are open, skilled, and comfortable in their discussion of sex-related topics. The present study examined the content and extent of sexual communication between parents and their adolescents, and the influence of selected primary demographic (age and gender), sociodemographic (Hispanic ethnicity, education, and religious attendance in a typical month), and psychological (comfort, knowledge, and difficulties) factors on number of topics parents discussed with their adolescents.

Overall, only a quarter of the parents had discussed all six topics. One half of the parents had discussed using protection, but $71 \%$ had discussed STIs, which suggests that in discussions with their adolescents, parents tend to focus more on the negative consequences of sex than the positive consequences of using protection if one is sexually active.

As anticipated, the number of topics discussed increased with adolescents' age. We note, however, that, as asked, number of topics discussed is cumulative over time; therefore, this finding does not necessarily imply that parents of older adolescents communicate to a greater extent than do parents of younger adolescents. Instead, it indicates only a greater likelihood of having ever, at least
Table 4 Summary of hierarchical regression analysis for variables predicting number of topics discussed $(N=875)$

\begin{tabular}{|c|c|c|c|}
\hline Variable & $B$ & SE $B$ & $\beta$ \\
\hline \multicolumn{4}{|l|}{ Model 1} \\
\hline Adolescent age & 0.392 & 0.022 & $.550 * * *$ \\
\hline Adolescent gender (female) & -0.330 & 0.249 & -.076 \\
\hline Parent age & -0.004 & 0.078 & -.001 \\
\hline Parent gender (female) & 0.086 & 0.197 & .017 \\
\hline Parent-adolescent gender interaction & 0.599 & 0.286 & $.134 *$ \\
\hline \multicolumn{4}{|l|}{ Model 2} \\
\hline Adolescent age & 0.393 & 0.022 & $.552 * * *$ \\
\hline Adolescent gender (female) & -0.341 & 0.249 & -.079 \\
\hline Parent age & -0.045 & 0.082 & -.018 \\
\hline Parent gender (female) & 0.116 & 0.198 & .023 \\
\hline Parent-adolescent gender interaction & 0.596 & 0.286 & $.133 *$ \\
\hline Parent Hispanic ethnicity & 0.010 & 0.159 & .002 \\
\hline Parent education & 0.090 & 0.061 & .054 \\
\hline Parent religious attendance & 0.017 & 0.044 & .011 \\
\hline \multicolumn{4}{|l|}{ Model 3} \\
\hline Adolescent age & 0.371 & 0.019 & $.521 * * *$ \\
\hline Adolescent gender (female) & -0.185 & 0.223 & -.043 \\
\hline Parent age & -0.058 & 0.074 & -.023 \\
\hline Parent gender (female) & 0.182 & 0.178 & .036 \\
\hline Parent-adolescent gender interaction & 0.280 & 0.257 & .063 \\
\hline Parent Hispanic ethnicity & 0.191 & 0.147 & .044 \\
\hline Parent education & 0.003 & 0.055 & .002 \\
\hline Parent religious attendance & -0.004 & 0.040 & -.002 \\
\hline Parent perceived comfort & 0.679 & 0.070 & $.287 * * *$ \\
\hline Parent perceived knowledge & 0.342 & 0.089 & $.115 * * *$ \\
\hline \multicolumn{4}{|l|}{ Communication difficulties } \\
\hline \multicolumn{4}{|l|}{ Absence (reference) } \\
\hline Presence & $-\mathbf{0 . 3 3 9}$ & 0.139 & $-.071 *$ \\
\hline Missing & -1.059 & 0.242 & $-.124 * * *$ \\
\hline
\end{tabular}

once, discussed these topics over time. Had we asked about number of topics discussed in the past year, it is possible that the relationship would be curvilinear, such that the number of topics discussed would initially increase with age and then decrease with further increases in age. It is of note, however, that a finding from a recent study by Pluhar et al. (2008) indicated that even when a sexual communication scale reflected sexuality issues that are developmentally appropriate for younger children, mothers were still more likely to talk with older children.

Our parent gender main-effect hypothesis, that mothers would report a greater number of topics discussed than would fathers, was not supported. But consistent with our interaction hypothesis, the number of topics discussed was 
highest when the gender of the parent matched the gender of the adolescent; the effect of parent gender, however, was significant for daughters but not for sons. As with previous research (e.g., Swain et al. 2006), the greatest number of topics discussed was between mothers and daughters, and the fewest was between fathers and daughters. Contrary to our expectations, none of the socio-demographic variables had an incremental effect on sexual communication once the primary demographic variables were taken into account.

As hypothesized, greater parent-reported levels of comfort and knowledge predicted greater number of topics discussed, and the presence of sexual communication difficulties predicted lower number of topics discussed, beyond the effect of demographic variables. This finding is consistent with previous research indicating the predictive power of parental comfort and knowledge in sexual communication between parents and their adolescents (e.g., Byers et al. 2008).

Of the various types of difficulties reported by the $70 \%$ of the parents reporting sexual communication difficulties, age or developmental issues were the most common among both mothers and fathers of preadolescents. Although many parents might have beliefs or feelings about which topics are appropriate to discuss with their adolescents and at what age or developmental level to discuss them, these commonly reported age or developmental difficulties among the parents of preadolescents in our study might be addressed through parent education and support. Professional organizations recommend that children begin to be exposed to age-appropriate comprehensive sexuality education topics as early as age 5 years (e.g., National Guidelines Task Force 2004). For parents who experience age or developmental difficulties in talking with their preadolescents about sex, guidance on which topics are developmentally appropriate at different ages and developmental levels might be especially valuable.

The strong influence of perceived comfort and knowledge, combined with the independent role of difficulties experienced, reinforces the notion that sexual communication between parents and their adolescents can be universally challenging. Parents of both genders, all ages, and all socio-demographic characteristics might benefit from guidance on strategies for initiating sexual communication with their adolescents, developmental appropriateness of specific topics, and ways to increase their knowledge and improve their comfort. Parents may also benefit from understanding the important role they play in their children's early and ongoing sexual socialization and how this socialization interacts with the sex education most adolescents receive in school (Shtarkshall et al. 2007).
Parents begin influencing their children's sexual development through sexual socialization before they begin proactively discussing sexual topics with them, by verbally and nonverbally conveying their standards regarding respect for others, affection, attitudes toward nudity, and so forth (Lefkowitz and Stoppa 2006; Shtarkshall et al. 2007). At the same time, sexual communication is more than the explicit discussion of sexual intercourse; it also encompasses discussion of nonsexual relationships, respect, sexual pleasure, decision making, and many other topics. The extent of sexual communication should increase and the topics covered should evolve as children age and develop, beginning around 5 years of age and continuing through young adulthood. With increasing sexual communication, various challenges arise for parents, often tied to their lessthan-optimal knowledge and comfort levels, including issues about what is appropriate to cover at what age. These challenges can sabotage their communications with and ultimately the healthy sexual development of their children. Education and support should be widely available for parents to help them become more effective sexual communicators.

We note several limitations associated with this research. In taking advantage of the efficiency, power, and generalizability of a large, representative, statewide telephone survey, we collected the open-ended responses with a minimum of probing and follow-up questioning. Self-reported difficulties in talking with adolescents about sex and relationships might not provide a complete and unbiased account of the nuances of parent-adolescent sexual communication. In-depth questioning and probing about these topics with a smaller representative sample might provide additional useful information and insights. Of additional note is that our study examined only parents' perceptions of parent-adolescent sexual communication, and research evidence suggests that parents and their children often have different perceptions of frequency and extent of sexual communication (see DiIorio et al. 2003). Moreover, although the six sex education topics we used in our study are representative of the harm-reduction focus of mainstream approaches to sex education, including positive sexuality topics as part of the list of topics discussed would have added value to our scale of number of topics discussed. A further caveat is that many languages are spoken by California parents, whereas resource constraints limited our data collection to English and Spanish languages only. Thus the results reported here are not precisely representative of the full population of households with adolescents in California, and specifically, they may underrepresent non-Englishspeaking Asian American parents. Yet, much research of this type is conducted only in English, and the advantage of our study is that we were able to include the one-third 
of our sample who preferred or required to be interviewed in Spanish. Finally, our telephone survey excluded households without a telephone.

Most parents want to be at the forefront of the conveyance of information, and values, about sex and sexuality to their adolescents. The majority of the parents in our sample, however, experienced some type of difficulty in communicating with their adolescents about these topics, and parents' comfort and knowledge in this area appear to be strongly predictive of such communication taking place. Parentadolescent communication about sex is widely viewed as a key foundation of an adolescent's sexual socialization and sexuality education, and as a positive influence on adolescent sexual health outcomes (Shtarkshall et al. 2007). Our use of a representative statewide sample of households with adolescents from a large and diverse state to investigate factors that predict this communication, together with parents' qualitative perspectives on their experiences in this area, adds to the existing research that can inform efforts to promote sexual communication and support parents in becoming more motivated, more comfortable, and more effective communicators. Future research should strive to use representative samples and to utilize in-depth questioning with smaller samples to provide useful insight on the specific issues that can constrain or facilitate effective parent-adolescent sexual communication.

Acknowledgments This study was funded by grants from The California Wellness Foundation and the William and Flora Hewlett Foundation. Thanks to Paul Gibson, Chris Berry, Carmen R. Nevarez, Alice Huang, Jessica Lin, Wendy L. Constantine, Veronica Raymonda, Gerald Sumner, Michael Kupkowski, and the California Adolescent Sexual Health Work Group for consultation and review. Survey data were collected by Quantum Market Research in Oakland, CA.

Open Access This article is distributed under the terms of the Creative Commons Attribution Noncommercial License which permits any noncommercial use, distribution, and reproduction in any medium, provided the original author(s) and source are credited.

\section{References}

American Association for Public Opinion Research. (2006). Standard definitions: Final dispositions of case codes and outcome rates for surveys (4th ed.). Lenexa, KS: Author.

Byers, E. S., Sears, H. A., \& Weaver, A. D. (2008). Parents' reports of sexual communication with children in kindergarten to Grade 8. Journal of Marriage and Family, 70, 86-96. doi:10.1111/j.17413737.2007.00463.x.

Constantine, N. A., Jerman, P., \& Huang, A. X. (2007a). California parents' preferences and beliefs regarding school-based sex education policy. Perspectives on Sexual and Reproductive Health, 39, 167-175. doi:10.1363/3916707.

Constantine, N. A., Slater, J., \& Carroll, J. (2007b). Motivational aspects of community support for school-based comprehensive sexuality education. Sex Education, 7, 421-439. doi:10.1080/ 14681810701636002.

Dilorio, C., Pluhar, E., \& Belcher, L. (2003). Parent-child communication about sexuality: A review of the literature from 19802002. Journal of HIV/AIDS Prevention \& Education for Adolescents \& Children, 5(3/4), 7-32. doi:10.1300/J129v05 n03_02.

Eisenberg, M. E., Sieving, R. E., Bearinger, L. H., Swain, C., \& Resnick, M. D. (2006). Parents' communication with adolescents about sexual behavior: A missed opportunity for prevention? Journal of Youth and Adolescence, 35, 893-902. doi:10.1007/ s10964-006-9093-y.

Guilamo-Ramos, V., Dittus, P., Jaccard, J., Goldberg, V., Casillas, E., $\&$ Bouris, A. (2006). The content and process of motheradolescent communication about sex in Latino families. Social Work Research, 30, 169-181.

Hayes, A. F., \& Matthes, J. (2009). Computational procedures for probing interactions in OLS and logistic regression: SPSS and SAS implementations. Behavior Research Methods, 41, 924-936.

Jaccard, J., Dittus, P. J., \& Gordon, V. V. (2000). Parent-teen communication about premarital sex: Factors associated with the extent of communication. Journal of Adolescent Research, 15, 187-208. doi:10.1177/0743558400152001.

Jaccard, J., Dodge, D., \& Dittus, P. (2002). Parent-adolescent communication about sex and birth control: A conceptual framework. New Directions for Child and Adolescent Development, 97, 9-41.

Lefkowitz, E. S. (2002). Beyond the yes-no question: Measuring parent-adolescent communication about sex. New Directions for Child and Adolescent Development, 97, 43-56.

Lefkowitz, E. S., \& Stoppa, T. M. (2006). Positive sexual communication and socialization in the parent-adolescent context. New Directions for Child and Adolescent Development, 12, 39-55. doi:10.1002/cd.161.

Lehr, S. T., Demi, A. S., DiIorio, C., \& Facteau, J. (2005). Predictors of father-son communication about sexuality. Journal of Sex Research, 42, 119-129.

Markham, C. M., Lorman, D., Gloppen, K. M., Peskin, M. F., Flores, B., Low, B., et al. (2010). Connectedness as a predictor of sexual and reproductive health outcomes for youth. Journal of Adolescent Health, 46(3, Suppl.), 23-41. doi:10.1016/j.jadohealth. 2009.11.214.

Miller, B. C., Benson, B., \& Galbraith, K. A. (2001). Family relationships and adolescent pregnancy risk: A research synthesis. Developmental Review, 21, 1-38. doi:10.1006/drev.2000. 0513.

Miller, K. S., Fasula, A. M., Dittus, P., Wiegand, R. W., Wyckoff, S. C., \& McNair, L. (2007). Barriers and facilitators to maternal communication with preadolescents about age-relevant sexual topics. AIDS and Behavior,. doi:10.1007/s10461-007-9324-6.

National Guidelines Task Force. (2004). Guidelines for comprehensive sexuality education: Kindergarten through 12th grade (3rd ed.). Retrieved March 25, 2010, from Sexuality Information and Education Council of the United States Web site: http://www. siecus.org/_data/global/images/guidelines.pdf.

Pluhar, E. I., DiIorio, C. K., \& McCarty, F. (2008). Correlates of sexuality communication among mothers and 6-12-year-old children. Child: Care, Health and Development, 34, 283-290. doi:10.1111/j.1365-2214.2007.00807.x.

Shtarkshall, R. A., Santelli, J. S., \& Hirsch, J. S. (2007). Sex education and sexual socialization: Roles for educators and parents. Perspectives on Sexual and Reproductive Health, 39, 116-119. doi:10.1363/3911607.

Steinberg, L. (2001). We know some things: Parent-adolescent relationships in retrospect and prospect. Journal of Research on Adolescence, 11(1), 1-19. doi:10.1111/1532-7795.00001. 
Swain, C. R., Ackerman, L. K., \& Ackerman, M. A. (2006). The influence of individual characteristics and contraceptive beliefs on parent-teen sexual communications: A structural model. Journal of Adolescent Health, 38, 753.e9-753.e18. doi: 10.1016/j.jadohealth.2005.08.015.

Whitaker, D. J., Miller, K. S., May, D. C., \& Levin, M. L. (1999). Teenage partners' communication about sexual risk and condom use: The importance of parent-teenager discussions. Family Planning Perspectives, 31, 117-121.

Wilson, E. K., Dalberth, B. T., Koo, H. P., \& Gard, J. C. (2010). Parents' perspectives on talking to preteenage children about sex. Perspectives on Sexual and Reproductive Health, 42, 56-63. doi: $10.1363 / 4205610$

\section{Author Biographies}

Petra Jerman is a research psychologist specializing in adolescent sexual health policy at the Public Health Institute's Center for Research on Adolescent Health and Development. She received her
Ph.D. in forensic psychology at the California School of Professional Psychology in 2003, and her M.P.H. in interdisciplinary public health at the University of California, Berkeley School of Public Health in 2006. Jerman's research has focused on the sexual health needs of foster youth, the incidence and cost of sexually transmitted infections among youth in California, and the use of evidence in the sex education debates.

Norman A. Constantine is director of the Public Health Institute's Center for Research on Adolescent Health and Development, and clinical professor of community health and human development at the University of California, Berkeley. He received his Ph.D. in educational psychology from the University of Oregon. Constantine's major research interests include adolescent sexuality and reproductive health, adolescent health policy, and motivated scientific reasoning. 